\title{
IDENTIFICAÇÃO DA ZONA DE DISPERSÃO SALINA COM APLICAÇÃO DOS MÉTODOS ELÉTRICO E ELETROMAGNÉTICO NO DOMÍNIO DA FREQÜÊNNCIA NO AQÜÍFERO COSTEIRO DE PLAYA PANAMÁ, COSTA RICA
}

\author{
ELECTRICAL AND ELECTRICMAGNETIC METHODS (FREQUENCY DOMAIN) APPLIED TO THE \\ IDENTIFICATION OF SALINE DISPERSION ZONE IN PLAYA PANAMA COSTAL AQUIFER, COSTA RICA
}

\author{
Daniel Murilo Montoya ${ }^{1}$, Ernani Francisco da Rosa Filho ${ }^{2}$, Eduardo Chemas Hindi ${ }^{2}$
}

\begin{abstract}
RESUMO Poucos aqüíferos costeiros têm sido estudados com métodos geofísicos na Costa Rica. Nenhum trabalho científico anterior utilizou simultaneamente dois métodos distintos para analisar as propriedades hidrogeológicas de algum aquífero costeiro na região do presente estudo, e particularmente para a definição da cunha de intrusão salina. A zona de Playa Panamá, na região pacifica noroeste do país, apresenta um típico aqüífero costeiro de moderado potencial, sendo que seu uso principal é enfocado para o abastecimento turístico. A geometria do aqüífero foi avaliada por meio da aplicação de Sondagens ElétricasVerticais (SEVs) e de condutivimetria no domínio da freqüência. A zona de dispersão salina também foi analisada empregando ambas as técnicas além da aplicação de um caminhamento elétrico com dispositivo Wenner. Os resultados foram complementados com dados litoestrátigraficos, hidrogeológicos e hidroquímicos e revelaram uma variabilidade na espessura dos sedimentos que compõem o aqǘf́ero, sendo que esta diminui em direção ao mar. Ambos os métodos utilizados mostraram-se muito sensíveis à presença da zona de dispersão salina, sendo que ela estaria encaixada nos sedimentos a uma profundidade de até $15 \mathrm{~m}$ e uma distancia não maior do que $65 \mathrm{~m}$ desde a linha de maré alta.

Palavras-chave: Costa Rica, intrusão salina, geofísica ambiental

ABSTRACT In Costa Rica, only a few coastal aquifers have been studied with the employment of geophysical methods. No scientific investigation which uses simultaneously two different methods to analyze the hydrogeologic properties of coastal aquifers, particularly to define salt intrusion has been done before in the area of study.The aquifer of Playa Panama, localized on the Pacific Coast, in the northwest part of the country (picture 1), has a moderate hydric potential, to be used for tourist purposes. The Average monthly rainfall in the region is $1944 \mathrm{~mm} /$ year, the potencial evapotranpiration is of 1930 $\mathrm{mm} /$ year (table 1). The aquifer is composed of basaltic angular conglomerates, mainly eroded from the Nicoya Complex. The aquifer geometry was analyzed through the application of Vertical Electrical Soundings (VESs) using a Schlumberger array, and conductivity measurement in the frequency domain. The results were complemented with stratigraphic, hydrogeological and hydrochemical data and suggest a decreasing of the aquifer's thickness towards the sea, and a non polluted condition. The saline dispersion zone was also studied with both techniques, together with an electric section obtained with Wenner array. Both methods showed a high sensitivity in the area corresponding to the salt intrusion (pictures 8,9 ), which occurs at a depth of $15 \mathrm{~m}$ in the sediments and at a distance not exceeding $65 \mathrm{~m}$ landward from the high tide line.

Keywords: Costa Rica, salt intrusion, environmental geophysics
\end{abstract}

\section{INTRODUÇÃO}

Existem pelo menos 24 zonas aqüíferas costeiras individualizadas na Península de Nicoya, pertencente à Costa Rica. Durante as duas últimas décadas o modelo das políticas econômicas internacionais e o relativo contexto pacífico do país têm propiciado um crescimento das atividades produtivas dessa região, especialmente do turismo. Esta situação influi diretamente na exploração da água subterrânea. No contexto ambiental, a Costa Rica tem participado em convênios e convenções mundiais que procuram a conservação do recurso hídrico e o desenvolvimento sustentável dos territórios costeiros; espaços onde a vulnerabilidade dos aquíferos são possíveis de serem afetados por intrusão de água salgada. Playa Panamá é uma das zonas aquíferas da Península de Nicoya e atualmente apresenta pouco desenvolvimento de infra-estrutura turística. Porém, pretende-se implementar para os próximos anos a construção de grandes projetos hoteleiros nessa zona. O aqüífero de Playa Panamá é aproveitado também por algumas praias vizinhas, sendo que o recurso hídrico é, literalmente, exportado de uma bacia até outra. Esta situação, somada ao aumento da demanda, exigem o conhecimento do potencial do reservatório hídrico local, e particularmente do estágio atual do processo de intrusão salina, mencionado por Arellano e Vargas (2001).

Estudos geofísicos de superfície em aqüíferos costeiros começaram a ser feitos nos anos 80 no litoral Pacífico da Costa Rica.

\footnotetext{
${ }^{1}$ Curso de Pós-Graduação em Geologia Ambiental-LPH-DEGEOL-UFPR.( remdanni@yahoo.com)

${ }^{2}$ UFPR-DEGEOL-LPH-Laboratório de Pesquisas Hidrogeológicas (ernani@ufpr.br; híndi@ufpr.br)
} 
A intrusão salina foi pesquisada utilizando-se o método elétrico de resistividade. Protti (1981) e Arias, Vargas e Guérin (2003) aplicaram este método para determinar as principais formações hidrogeológicas, e estabelecer áreas de proteção de aqüíferos costeiros, para evitar a contaminação por intrusão salina.

Arias (2000 apud Arias 2002) executou um arranjo tipo pólo-pólo com caminhamento elétrico sobre sedimentos aluvionares da "Isla del Coco" para definir a zona de dispersão salina. Arias (2000, apud ARIAS, 2002) e Gómez (2005) realizaram avaliação geoelétrica com caminhamentos em aquíferos costeiros no noroeste da Península de Nicoya, com o objetivo de determinar a profundidade da água subterrânea e do topo do embasamento; a espessura dos depósitos quaternários; e a resistividade das formações geológicas. $\mathrm{O}$ uso de métodos eletromagnéticos em aquíferos costeiros na região limita-se ao estudo realizado por Arias (2002, apud ARIAS, 2002). Esse estudo avaliou feições gerais da condutividade elétrica das camadas do aqüífero, mas sem fazer considerações sobre a zona de dispersão salina. Protti (1981) utilizou prospecção geofísica com sísmica de refração para pesquisa de águas subterrâneas. Outros estudos em aqüíferos costeiros da Península de Nicoya foram realizados para avaliar de forma geral a intrusão salina, baseando-se em análises físico-químicas de águas de poços. Losilla (1993) menciona que amostras de água coletadas em poços apresentaram condutâncias específicas superiores a $1000 \mu \mathrm{Siemens} / \mathrm{cm}$, e lista nove praias com problemas de intrusão marinha. Arellano e Vargas (2001) utilizaram dados de condutividade elétrica para avaliar 24 áreas aquíferas costeiras; eles identificaram quatro locais com fortes indícios de intrusão salina, sendo que em nenhum dos casos tratou-se de Playa Panamá.

Neste trabalho foi usado conjuntamente o método elétrico com corrente contínua e o método eletromagnético no domínio da freqüência. Isto, para determinar o modelo conceitual unidimensional do aqǘfero e avaliar a intrusão salina, comparando-se os resultados em ambos os métodos. A combinação dos dados obtidos com dados hidroquímicos e hidrodinâmicos, constitui um instrumento para examinar o estágio espaço-temporal da interface água doce - água salgada.
A área de estudo é uma microbacia cuja abrangência corresponde a aproximadamente $22,2 \mathrm{~km}^{2}$. Esta área está inserida na região noroeste da Costa Rica, na província de Guanacaste, $25 \mathrm{~km}$ a sudoeste da cidade de Liberia (Figura 1). Playa Panamá constitui o limite norte da bacia e forma parte das praias que rodeiam Bahia Culebra no oceano Pacífico, sendo a extensão da zona litorânea de pouco mais de 2 $\mathrm{km}$.

\section{CONTEXTO HIDROGEOLÓGICO DO AQÜÍFERO}

Geotectonicamente o aqǘfero de Playa Panamá está situado dentro das bacias do antearco, o qual está associado à zona de subdução formada pela interação entre as placas tectônicas Cocos e Caribe. Estas bacias possuem pequenas áreas com depósitos sedimentários recentes, gerados a partir da deposição de material aluvial erodido das serras do antearco vulcânico e também gerados pela dinâmica costeira.

$\mathrm{Na}$ área de estudo existem três conjuntos litológicos (Figura 2). Na base da seqüência estratigráfica está o Complexo de Nicoya $(\mathrm{CN})$, o qual está formado por basaltos cretáceos e radiolaritas jurássicas, assim como por corpos intrusivos (gabros, doleritas e plagiogranitos) de idade cenomaniana (DENYER; ARIAS, 1993).

$\mathrm{O} \mathrm{CN}$ aflora entre as cotas de 0 e $170 \mathrm{~m}$ de altitude nos setores sudoeste e nordeste da bacia. Os basaltos formam solos de espessuras da ordem de 1 a $3 \mathrm{~m}$ e apresentam um fraturamento considerável por causa do tectonismo, principalmente no topo da unidade geológica. As radiolaritas não afloram dentro da bacia. $O$ intrusivo Potrero é um membro litológico do $\mathrm{CN}$, o qual aflora no extremo oeste da zona litorânea de Playa Panamá. Esta subunidade intrusiva distingue-se dos basaltos pela alteração arenitizada (DENYER; ARIAS, 1993). O contato superior do CN está representado pela Formação Bagaces, de idade Mioceno Superior-Plioceno. Esta unidade geológica está constituída por lavas ácidas; depósitos lacustres; e principalmente por ignimbritos; estas últimas rochas afloram no setor nordeste da bacia, em uma área de $2,4 \mathrm{~km}^{2} \mathrm{e}$ possuem uma espessura máxima de cerca de 30 $\mathrm{m}$, sendo que em alguns lugares, apresentam conglomerados basais. 


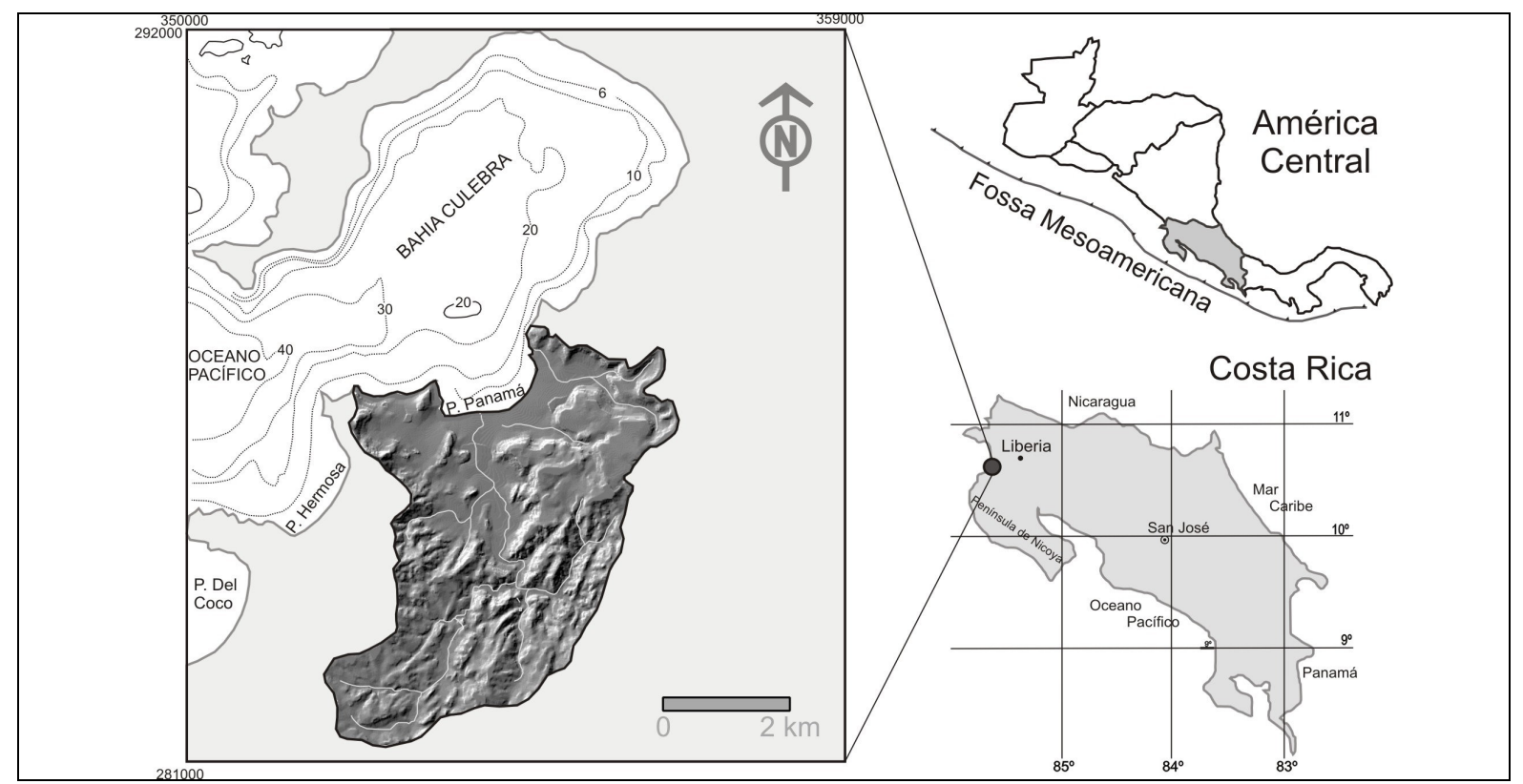

Figura 1- Mapa de localização da área de estudo.

Figure 1- Location of the study area.

No topo da seqüência cronoestratigráfica estão os sedimentos recentes, eles podem ser separados em depósitos costeiros e depósitos continentais.

Os depósitos costeiros concentram-se ao longo da faixa litorânea, sob a forma de pequenas dunas de areia espalhadas em uma zona de baixo mergulho $\left(0-2^{\circ}\right)$, eles têm entre 20 e $40 \mathrm{~m}$ de largura. Na desembocadura do rio Panamá forma-se um pequeno manguezal que possui material silto-argiloso.

$\mathrm{O}$ aqüífero atinge uma superfície de 3,9 $\mathrm{km}^{2}$ com mergulho suave $\left(0-5^{\circ}\right)$; é do tipo granular e livre, porém, em alguns setores apresenta um semiconfinamento relativo. $\mathrm{O}$ aquífero está composto por conglomerados angulares intercalados com materiais mais finos, e derivados das unidades geológicas mencionadas, sua espessura é variável e atinge até $27 \mathrm{~m}$. Os registros litológicos de 18 poços construídos em Playa Panamá revelaram a presença de uma camada argilosa no topo do aquiífero. A espessura média desta camada é de aproximadamente $6 \mathrm{~m}$ (Figura 3). A parte central da sequiência estratigráfica dos sedimentos continentais é formada por intercalações centimétricas de seixos angulosos e areia, com presença de lentes de argila, mostrando estruturas sedimentares como laminação paralela e cruzada. Todas essas características refletem pouco transporte do material, gerado em um ambiente de alta energia. O topo do embasamento $(\mathrm{CN})$ é irregular e apresenta profundidades superiores a $7 \mathrm{~m}$ segundo os registros litológicos de poços.

O clima da região é tropical seco. A faixa de variação de temperatura no ano é de 22 a $33^{\circ} \mathrm{C}$. A exposição solar é em média de 7,4 horas diárias. Os ventos são influenciados pela Zona de Convergência Intertropical (ZCIT), sendo que na estação seca predominam os ventos alísios de NE; na época chuvosa o processo inverte-se com ventos $\mathrm{W}$ e $\mathrm{SW}$ e a sua velocidade média é de $11 \mathrm{~km} / \mathrm{h}$. Segundo dados pluviométricos do Instituto Meteorológico Nacional (IMN 1988), a precipitação média anual em Playa Panamá (1977-1981) é de 1943 mm (Tabela 1). O período seco é bem marcado, ele inclui os meses de novembro até abril e tem uma média de chuva mensal de $22 \mathrm{~mm} / \mathrm{ano}$. A área de estudo não dispõe de dados de evaporação. 
Identificação da zona de dispersão salina com aplicação dos métodos elétrico e eletromagnético no domínio da freqüência no aqüífero costeiro de Playa Panamá, Costa Rica

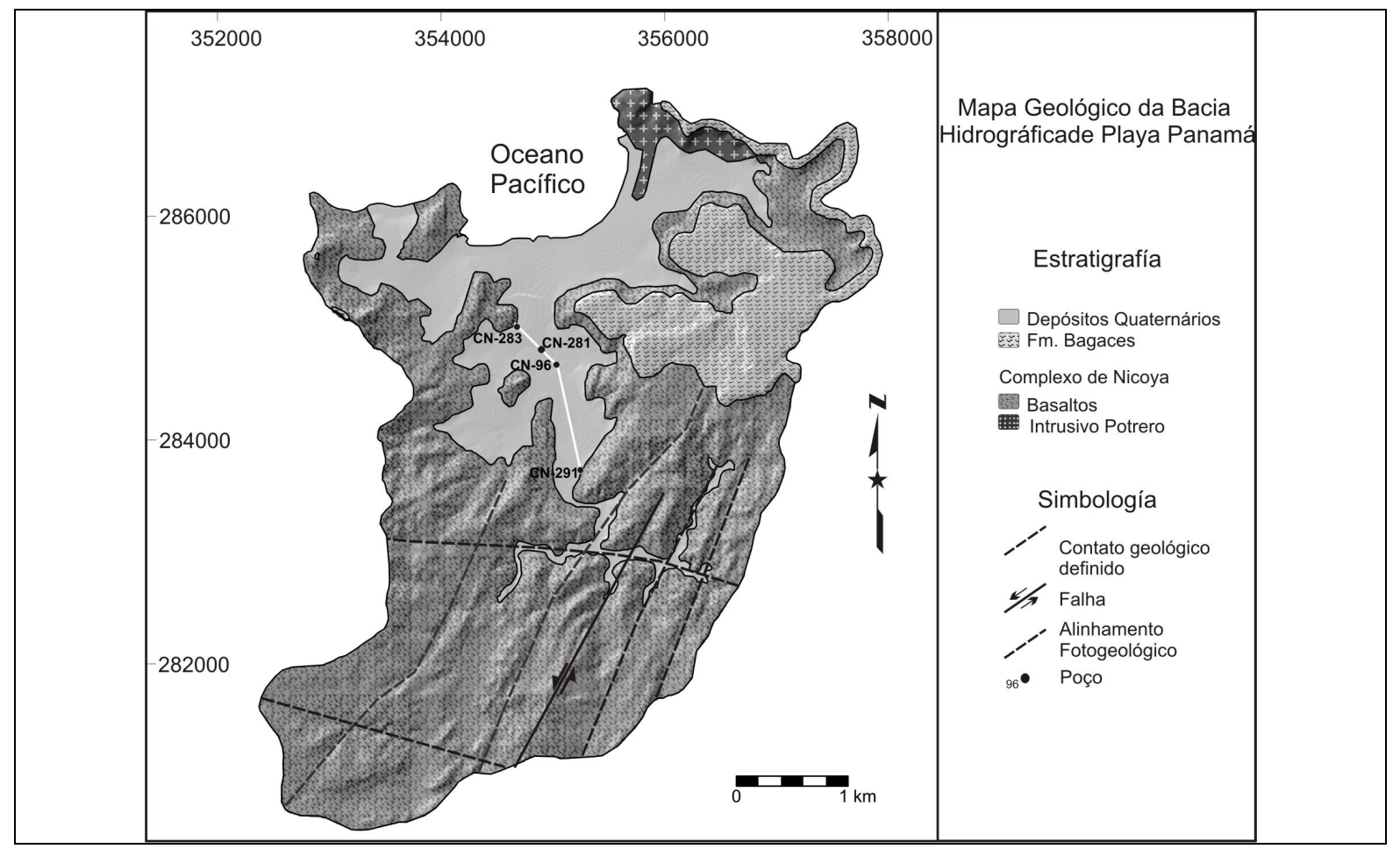

Figura 2 - Mapa geológico da zona da Bacia de Playa Panamá. A linha branca marca o perfil hidrogeológico da Figura 3.

Figure 3- Geologic map of Playa Panamá basin. White Line marks the cross-section in figure 3.

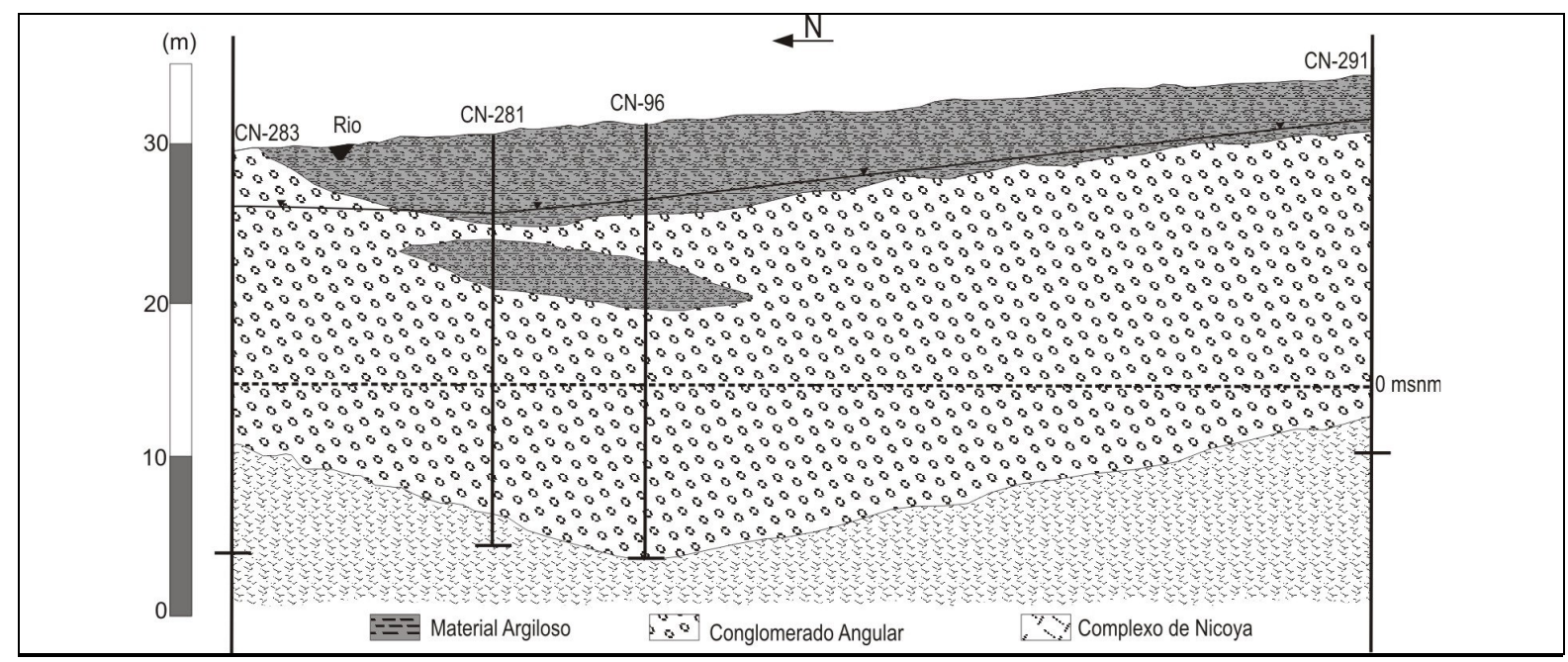

Figura 3 - Perfil Hidrogeológico idealizado da seção central do aquiífero de Playa Panamá

Figure 3- Hidrogeologic cross-section of Playa Panama's aquifer.

Tabela 1- Média mensal de chuva da estação pluviométrica Playa Panamá (1977-1981) e evaporação diária mensal da estação meteorológica Liberia (1971-2002).

Table 1- Average monthly rainfall and evaporation of Playa Panamá pluviometrical station for 1971-1981 period and Liberia meteorologic station for 1971-2002 period.

\begin{tabular}{cccccccccccccc}
\hline Fator (mm) & Jan & Fev & Mar & Abr & Mai & Jun & Jul & Ago & Set & Out & Nov & Dez & Total \\
\hline Chuva (Média) & 0.3 & 0.0 & 7.0 & 13.7 & 284.3 & 442.5 & 121.7 & 253.1 & 375.9 & 334.9 & 95.7 & 14.7 & 1943.9 \\
$\begin{array}{c}\text { Evaporação } \\
\text { (Diário) }\end{array}$ & 9.2 & 9.2 & 9.7 & 9.3 & 7.3 & 4.6 & 5.9 & 5.5 & 4.6 & 4.5 & 4.6 & 7.0 & - \\
$\quad$ ETP & 184.1 & 190.9 & 226.3 & 210.5 & 178.2 & 134.4 & 148.3 & 150.2 & 127.3 & 119.1 & 128.3 & 131.0 & 1928.7 \\
\hline
\end{tabular}


Porém, foram usados dados da estação mais próxima $(\sim 11 \mathrm{~km}$ de distância e $180 \mathrm{~m}$ de altitude) para calcular, por meio do método de Hargreaves, uma evapotranspiração potencial (ETP) média anual de $1928 \mathrm{~mm}$.

Segundo Herrera (1986) este método é definido pela equação:

$\mathrm{ETP}=\left[(0,17 x R A x \sqrt{T D}(0.0075)] \cdot\left(32+1,8^{\circ} \mathrm{C}\right] \mathrm{N}\right.$

Sendo:

ETP = Evapotranspiração potencial média mensal (mm)

RA = Radiação no topo da atmosfera (equivalente em $\mathrm{mm}$ diário de água evaporada)

${ }^{\circ} \mathrm{C}=$ Temperatura média mensal

$\mathrm{TD}=$ Diferença entre as temperaturas máxima e mínima média mensal $\left({ }^{\circ} \mathrm{C}\right)$

$\mathrm{N}=$ Número de dias do mês

A evapotranspiração real (ETR) deve ser menor do que a ETP, sendo que o seu valor poderia ser maior na área de estudo do que no lugar onde está localizada a estação Liberia, cuja distância em relação à costa é maior. Foi assumido que a recarga do aquífero é direta; a recarga lateral por fraturamento do $\mathrm{CN}$ não deve ser descartada, mas é difícil de quantificar com os dados disponíveis. Dados hidrogeoquímicos poderiam sustentar a hipótese da recarga direta. Resultados de 10 amostras coletadas em poços desde o ano 2000 indicam águas do tipo bicarbonatadas cálcio-magnesianas.

A transmissividade dos materiais que constituem o aqüífero está na ordem de 0,24 (ARELLANO; VARGAS, 2001) a $4,1 \times 10^{3}$ $\mathrm{m}^{2} / \mathrm{d}$, sendo valores representativos de aqüíferos livres. A capacidade de produção atual dos poços é de 1 a $10 \mathrm{~L} / \mathrm{s}$.

O uso atual do aqüífero de Playa Panamá sugere condições estáveis para a relação da interface água doce - água salgada. Por tratar-se de um aqüífero hidrogeologicamente simples, pode implicar a presença de uma única zona de dispersão salina. O emprego de métodos elétrico em corrente contínua e de condutívimetria no domínio da frequiência, visa um melhor entendimento da estratigrafia do aqǘfero e da cunha salina.

\section{MÉTODO ELÉTRICO COM CORRENTE CONTÍNUA}

Em estudos de águas subterrâneas o uso de métodos de corrente contínua (CC) é bem conhecido. A estimativa da resistividade do subsolo a partir da sua resistividade aparente representa uma forma de avaliar espessuras de camadas geológicas; de profundidades de superfícies potenciométricas; e de zonas de dispersão salina, entre outros. Para aquíferos homogêneos com presença de argila, a resistividade do conjunto rochoso é definida por:

$$
1 / \rho_{\mathrm{r}}=\left(\mathrm{V}_{\mathrm{Cl}} \mathrm{S}_{\mathrm{w}} / \rho_{\mathrm{cl}}\right)+\left(\varphi^{\mathrm{m}} \mathrm{S}^{2}{ }_{\mathrm{w}} / \mathrm{a} \mathrm{p}_{\mathrm{w}}\right)
$$

$\mathrm{a}, \mathrm{m}, \mathrm{n}$ são constantes que dependem da formação rochosa

$\mathrm{p}_{\mathrm{w}}=$ resistividade dos poros do fluido

$\varphi=$ porosidade da formação rochosa

$\mathrm{S}$ = grau de saturação

$\mathrm{V}_{\mathrm{Cl}}=$ volume da fração argilosa

$\mathrm{P}_{\mathrm{r}}=$ resistividade da fração rochosa

$\rho_{\mathrm{cl}}=$ resistividade da fração argilosa

Essa fórmula é conhecida como equação de Simandoux (WARD, 1990).

Neste trabalho, o aquiífero de Playa Panamá foi considerado como homogêneo, estando composto principalmente de areias grossas e seixos. Neste caso, é difícil quantificar o volume e a resistividade da fração argilosa a partir dos dados de resistividade do corpo de sedimentos. As resistividades medidas nos sedimentos do aquífero representam, basicamente, conteúdos relativos de materiais de texturas granulométricas diferentes.

O método elétrico utiliza uma fonte geradora de corrente (I) que é injetada no solo através de eletrodos (A e B), a corrente produz uma diferença de potencial (V) que é medida nos eletrodos de potencial ( $\mathrm{M}$ e N). A disposição relativa dos eletrodos é conhecida como arranjo elétrico e depende das características do processo ou atividade a ser estudada. Geralmente, o método é utilizado nas formas de Sondagens Elétricas Verticais (SEVs) e caminhamentos elétricos, os primeiros visam obter a variação vertical da resistividade aparente abaixo de um ponto único e são usados para o estabelecimento de camadas litológicas horizontais em profundidade. A segunda técnica visa obter um perfil ao longo de uma linha de pontos, com a vantagem de analisar a variação lateral e em profundidade do corpo geológico estudado, ou em casos como a intrusão salina, da variação na posição da interface água doce-água salgada. A profundidade de pesquisa é proporcional (não diretamente) à distância $A B / 2$. Para o presente trabalho, foram utilizadas ambas as técnicas de 
pesquisa. $\mathrm{O}$ equipamento usado foi o modelo Terrameter SAS 1000 da $\mathrm{ABEM}^{\circledR}$ que utiliza 4 eletrodos ativos.

\section{MÉTODO ELETROMAGNÉTICO NO DOMÍNIO DA FREQÜÊNCIA}

Os métodos eletromagnéticos apresentam variadas técnicas, as quais são utilizadas em muitas aplicações hidrogeológicas, entre elas pode-se citar a localização de materiais mais grossos e o mapeamento do topo de embasamentos e de intrusões salinas. Esta última aplicação é bastante utilizada com a técnica Eletromagnética no Domínio do Tempo (TDEM). Nesta pesquisa, também foi empregada a condutivimetria no domínio da freqüência como o objetivo de conhecer a efetividade da técnica em este tipo de aplicação. Deidda et al. (2003) usaram esta técnica para a delimitação de cunha salina, a qual segundo estes autores embora forneça resultados menos quantitativos, ela tem a vantagem de ser rápida e com facilidade operativa.

Os princípios do método eletromagnético e da instrumentação empregada são bem descritos por McNeill $(1980,1985,1990)$ e Spies; Frischknecht (1987). O condutivímetro EM34-3 inclui duas bobinas separadas por um cabo elétrico, sendo que uma delas é a bobina transmissora, a qual é energizada com corrente oscilante com uma frequiência característica. Este processo gera um campo magnético variável primário que produz ondas eletromagnéticas no solo, as quais criam um campo magnético secundário. A razão entre ambos os campos magnéticos é proporcional à condutividade do subsolo, assim a condutividade do corpo rochoso é medida diretamente na bobina receptora. McDonald, Davies e Peart (2001) atestam que a condutividade elétrica no subsolo é controlada principalmente por três fatores: a porosidade, a presença e natureza do fluído e o conteúdo de argila.

A profundidade investigada pelo EM34-3 depende da frequiência, da estrutura elétrica da terra e do espaçamento e configuração das bobinas (Monteiro Santos 2004).

O presente trabalho faz uso de duas configurações de bobinas, o modo de dipolo horizontal (HMD) e o modo de dipolo vertical (VMD). No primeiro as bobinas são colocadas verticalmente sob o mesmo plano e no segundo as bobinas são colocadas horizontalmente na superfície do solo.
O HMD é menos susceptível aos deslocamentos das bobinas, situação que permite obter dados de condutividade mais próximos à condutividade real. $\mathrm{O}$ modo HMD atinge uma profundidade de pesquisa igual a 0,75 vezes distância de separação entre as duas bobinas; o modo HMD atinge o dobro de profundidade. Os cabos que unem as bobinas têm comprimentos fixos de 10, 20 e $40 \mathrm{~m}$ e trabalham com frequiências de $6.4, \quad 1.6$ e $0.4 \mathrm{KHz}$, respectivamente (McNEILL, 1980).

\section{APLICAÇÕES}

Duas aplicações específicas dos métodos geofísicos empregados são discutidas. A primeira aplicação consiste em estimar a geometria conceitual do aquífero através da determinação de diferentes horizontes hidrogeológicos, particularmente do embasamento. A segunda aplicação visa identificar a presença da interface água doce - água salgada. Foram analisados dados obtidos a partir de SEVs e caminhamentos elétricos e eletromagnéticos.

\section{MODELO CONCEITUAL DO AQÜÍFERO}

\section{SEVs}

Utilizaram-se dados de resistividade aparente de 5 SEVs efetuadas sobre os depósitos que formam o aquífero (Figura 4). O objetivo foi conhecer a sua espessura, e a profundidade do nível freático e do topo do embasamento. Foi utilizado o arranjo Schlumberger com abertura $\mathrm{AB} / 2$ máxima de $100 \mathrm{~m}$, e deu-se ênfase aos primeiros $40 \mathrm{~m}$ de $A B / 2$ para avaliar em detalhe as feições resistivas do aqüífero. Para realizar as inversões dos dados, considerou-se um modelo geral unidimensional de quatro camadas (solo, zona não saturada, zona saturada e embasamento). Os resultados foram comparados com os registros hidrogeológicos dos 5 poços próximos a cada SEV.

A tabela 2 mostra a informação hidrogeológica disponível dos 5 poços. O "n.e." representa a profundidade do lençol freático no momento de serem construídos os poços; o "n.d." é a profundidade do nível dinâmico.

O perfil geológico geral para cada poço foi sintetizado em três camadas; sendo que no topo está o solo que é pouco desenvolvido e formado principalmente por material argiloso; a parte central corresponde ao corpo do aquífero e por último está o embasamento basáltico.

A figura 5 mostra as curvas de inversão da resistividade para cada SEV junto com o perfil hidrogeológico de cada poço. 


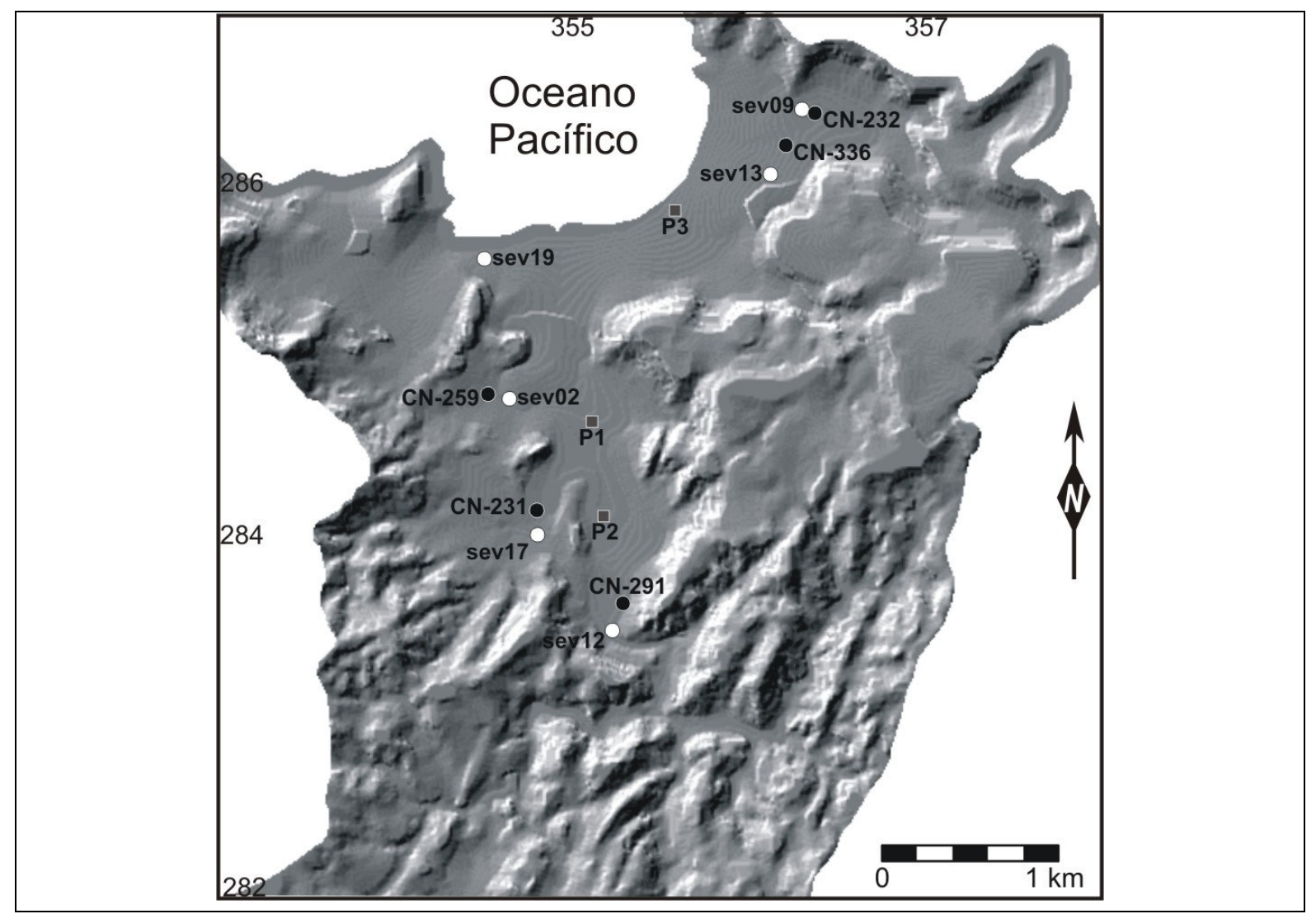

Figura 4 - Localização de poços, SEVs e perfis eletromagnéticos realizados em Playa Panamá. Figure 4- Localization of wells, SEVs and electromagnetic sections made in Playa Panamá.

Tabela 2 - Dados hidrogeológicos de poços em Playa Panamá.

Table 2 - Hidrogeologic information of Playa Panamá's wells.

\begin{tabular}{|c|c|c|c|c|c|c|c|c|}
\hline Poço & ano & n.e. (m) & n.d. (m) & $\begin{array}{l}\text { Vazão } \\
(\mathbf{L} / \mathbf{s})\end{array}$ & $\begin{array}{c}\text { n.e. } \\
(2006)\end{array}$ & $\begin{array}{l}\text { n.d. } \\
(\mathbf{2 0 0 6})\end{array}$ & $\begin{array}{l}\text { Vazão } \\
(\mathbf{2 0 0 6 )}\end{array}$ & $\begin{array}{l}\text { Descrição } \\
\text { Geológica } \\
\end{array}$ \\
\hline $\begin{array}{l}\text { CN- } \\
231\end{array}$ & $\begin{array}{c}198 \\
9\end{array}$ & 9.2 & 15 & 8.0 & - & - & 0.0 & $\begin{array}{c}0-7 \mathrm{~m} \text { argila; } 7-20 \text { material } \\
\text { coluvio-aluvionar; } 20-36 \mathrm{~m} \\
\text { basaltos }\end{array}$ \\
\hline $\begin{array}{l}\mathrm{CN}- \\
232 \\
\end{array}$ & $\begin{array}{c}198 \\
9 \\
\end{array}$ & 6.3 & 15.4 & 8.3 & - & 9.6 & 7.0 & $\begin{array}{l}0-7 \mathrm{~m} \text { argila; } 7-21 \mathrm{~m} \text { basalto } \\
\text { alterado }\end{array}$ \\
\hline $\begin{array}{l}\text { CN- } \\
259\end{array}$ & $\begin{array}{c}199 \\
3\end{array}$ & 5.0 & - & 6.0 & 7.0 & - & 0.0 & $\begin{array}{c}0-4 \text { m capa arenosa-argilosa; } 4- \\
23 \mathrm{~m} \text { material aluvional }\end{array}$ \\
\hline $\begin{array}{l}\text { CN- } \\
291\end{array}$ & $\begin{array}{c}199 \\
4\end{array}$ & 2.8 & - & - & - & - & - & $\begin{array}{l}\text { 0-4 m capa silte-arenosa; } 4-23 \\
\text { m material colúvio-aluvionar; } \\
23-26 \text { m basaltos }\end{array}$ \\
\hline $\begin{array}{l}\text { CN- } \\
336\end{array}$ & $\begin{array}{c}199 \\
6\end{array}$ & 6.8 & 7.84 & 3.0 & - & 8.7 & 7.0 & $\begin{array}{c}0-1.2 \mathrm{~m} \text { capa arenoso; } 1.2-5 \mathrm{~m} \\
\text { material coluvio-aluvionar;5-10 } \\
\text { m siltes-argilas; } 10-23 \mathrm{~m} \\
\text { material colivio-aluvionar }\end{array}$ \\
\hline
\end{tabular}

As formas das curvas são muito semelhantes, sendo que as diferenças entre elas refletem as variações nas espessuras das camadas estabelecidas para o modelo. As curvas com concavidade acentuada refletem uma profundidade maior do embasamento, o qual é representado no ramo final ascendente de cada curva, e atinge inclinações quase idênticas. $\mathrm{O}$ solo apresentou valores de resistividade de 32 a $500 \Omega \mathrm{m}$. Os altos valores de resistividade das SEVs associadas aos poços CN-291 (500 $\Omega \mathrm{m})$ e o CN-336 (100 $\Omega \mathrm{m})$, ocorrem porque a primeira SEV foi feita sobre os sedimentos arenosos pouco consolidados do rio Panamá, e a segunda ao longo de uma estrada que está situada sobre um pequeno aterro de aproximadamente $1 \mathrm{~m}$ de 
espessura. O registro litológico deste último poço também indica um topo arenoso. A resistividade do solo estaria na faixa de 32 a $40 \Omega \mathrm{m}$ e é controlada, principalmente, pela presença de areia e argila.

A zona não saturada (ZNS) mostrou valores de resistividade entre 13 a $60 \Omega \mathrm{m}$. Em geral, os valores diminuem em função do solo. A porosidade efetiva neste horizonte é provavelmente menor e a umidade ligeiramente maior do que no solo. Os valores são controlados basicamente pelo conteúdo de argilas. $\mathrm{O}$ valor de $60 \Omega \mathrm{m}$ corresponde à SEV feita sobre o rio Panamá, aqui a ZNS deve conter mais fração de material arenoso, sendo que aumenta a sua resistividade.

A zona saturada (ZS) apresenta valores de resistividade entre 10 a $30 \Omega \mathrm{m}$. Embora o material seja de textura mais grossa, o conteúdo de água nos poros dos sedimentos e a alteração do topo do embasamento fazem com que a resistividade apresente valores menores.

$\mathrm{O}$ embasamento ficou bem identificado em cada uma das sondagens elétricas, a resistividade dele é relativa, sendo que os resultados variam com o grau de alteração, com o fraturamento, com tipo de preenchimento e abertura nas fraturas, com o conteúdo de água e com a espessura atingida por cada SEV, entre outros.

Na tabela 3 estão indicados os valores de espessuras e resistividades dos conglomerados angulares, os quais foram obtidos a partir dos dados das SEVs e a informação litoestratigráfica dos poços construídos em Playa Panamá. Os resultados de $3 \mathrm{SEV}$ sossuem uma diferença entre o dado registrado e o dado obtido menor do que $8 \%$, valor considerado aceitável dentro do erro associado a cada inversão. No caso da SEV PPM12, o erro associado obedeceria aos seguintes fatores: menor acoplamento dos eletrodos nos sedimentos arenosos do rio; a distância relativa ao poço CN-291, a qual implica mudanças locais na profundidade do embasamento, e por último, ao deslocamento da linha da perfilagem devido às condições geomorfológicas locais. Por outro lado, a diferença entre os valores da SEV PPM02 e o poço $\mathrm{CN}-232$ estaria relacionada com a qualidade da descrição litológica. Segundo o registro litológico, existiriam $14 \mathrm{~m}$ de basalto alterado no subsolo, sendo que mais bem poderiam corresponder aos sedimentos recentes (formados pela alteração dos basaltos). Assumindo isso, a espessura dos sedimentos seria de $21 \mathrm{~m} \mathrm{e}$ a diferença entre o valor invertido e o valor registrado diminuiria para $5 \%$. 


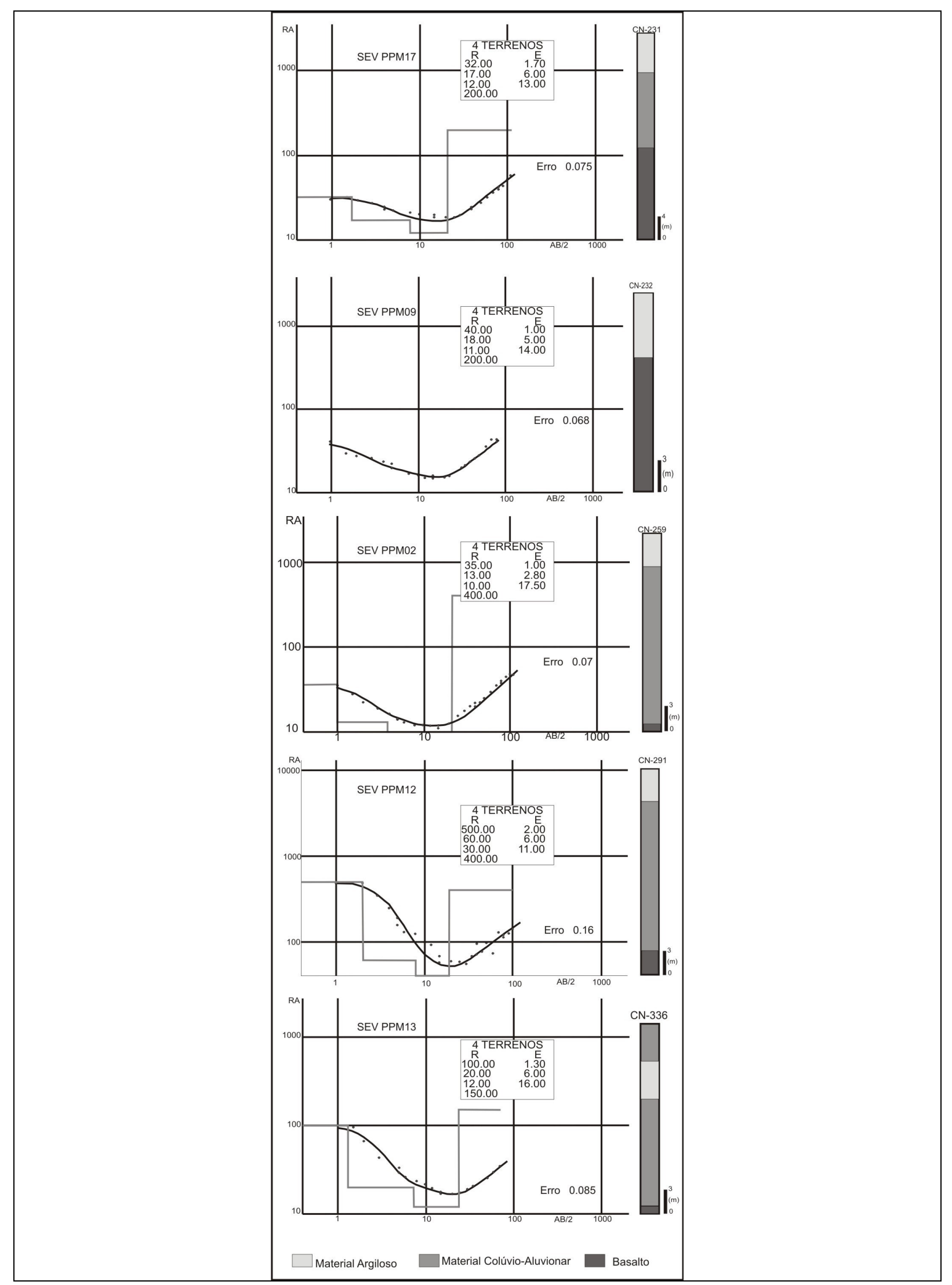

Figura 5 - Resultados da inversão da resistividade aparente das SEVs e perfis litológicos de cada poço. Figure 5 -Results of apparent resistivity inversion from the SEVs and litologic section for each well. 
Tabela 3 - Dados comparativos entre os resultados das inversões de resistividade e poços nos depósitos recentes. Table 3 - Comparation of results of inversion data with the well's lithostratigraphic information.

\begin{tabular}{|c|c|c|c|c|c|}
\hline & $\begin{array}{c}\text { Separação } \\
\text { Relativa (m) }\end{array}$ & Resistividade ( $\mathbf{\Omega m})$ & $\begin{array}{c}\text { Espessura } \\
\text { (m) }\end{array}$ & $\begin{array}{c}\text { Diferença } \\
(\%)\end{array}$ & $\begin{array}{c}\text { Erro da } \\
\text { inversão }(\%)\end{array}$ \\
\hline $\begin{array}{l}\text { SEV PPM17 } \\
\text { Poço CN-231 }\end{array}$ & 140 & $12-32$ & $\begin{array}{c}20.7 \\
20\end{array}$ & 3.5 & 7.5 \\
\hline $\begin{array}{l}\text { SEV PPM09 } \\
\text { Poço CN-232 }\end{array}$ & 80 & $11-40$ & $\begin{array}{c}20 \\
7\end{array}$ & 65 & 6.8 \\
\hline $\begin{array}{l}\text { SEV PPM02 } \\
\text { Poço CN-259 }\end{array}$ & 120 & $10-35$ & $\begin{array}{c}21.3 \\
23 \\
\end{array}$ & 7.3 & 7.0 \\
\hline $\begin{array}{l}\text { SEV PPM12 } \\
\text { Poço CN-291 }\end{array}$ & 255 & $30-500$ & $\begin{array}{l}19 \\
23\end{array}$ & 17 & 16.3 \\
\hline $\begin{array}{l}\text { SEV PPM13 } \\
\text { Poço CN-336 }\end{array}$ & 190 & $12-100$ & $\begin{array}{c}23.3 \\
23\end{array}$ & 1.3 & 8.5 \\
\hline
\end{tabular}

\section{Condutivimetria}

Para complementar o modelo conceitual do aqüífero foram utilizados dados de dois caminhamentos eletromagnéticos (P1 e P2), realizados sobre a unidade quaternária (Figura 4). Os perfis atingiram 75 e $230 \mathrm{~m}$ de comprimento, e foram empregados os três espaçamentos entre bobinas disponíveis no condutivímetro, tanto para o modo VMD quanto para o HMD. Os dados de resistividade ( $\rho$ em $\Omega \mathrm{m}$ ) do aquíffero foram comparados com os dados de condutividade elétrica $\left(\sigma\right.$ em mmhos. $\left.\mathrm{m}^{-1}\right)$ obtidos com o condutivímetro. Para McDonald, Davies e Peart (2001), a relação entre estes parâmetros é $\sigma \rho=1000$. A Figura 6 mostra os perfis de condutividade elétrica e as interpolações dos valores de $\sigma$.

$\mathrm{O}$ perfil 1 mostra que a condutividade diminui com a profundidade. Nos primeiros $15 \mathrm{~m}$ de profundidade (aberturas de $10 \mathrm{~m}$ e $20 \mathrm{~m}$, exceto VMD-20) $\sigma$ atinge valores de 28 a 60 mmhos. $\mathrm{m}^{-1}(35 \mathrm{a} 18 \Omega \mathrm{m})$. Isto sugere a presença da camada argilosa no topo do aquífero e a existência de variações texturais laterais. A configuração de bobinas no modo HMD responde melhor às variações superficiais, sendo que a alta condutividade medida no modo HMD10 é devida às argilas e a presença do lençol freático. $\mathrm{Na}$ profundidade de $30 \mathrm{~m}$ os valores medidos de $\sigma$ foram de 18 a 28 mmhos.m ${ }^{-1}$ (55 a $35 \Omega \mathrm{m}$ ). Estes resultados corresponderiam com a parte superior do embasamento, possivelmente mais fraturado, o que aumenta o valor da resistividade. Aos $60 \mathrm{~m}, \sigma$ apresentou valores na faixa de 22 a 5 mmhos.m ${ }^{-1}$ (45 a $250 \Omega \mathrm{m}$ ). O resultado é similar ao obtido com as SEVs. Porém, deve ser considerado que o modo VMD-
40 é mais suscetível ao deslocamento das bobinas e pode oferecer valores maiores de $\sigma$.

O perfil 2, pelo contrário, mostra valores de $\sigma$ crescente com a profundidade. Os primeiros $30 \mathrm{~m}$ do subsolo (aberturas de 10, 20 e $40 \mathrm{~m}$, exceto VMD-40) atingiram valores de $\sigma$ entre 40 e 75 mmhos. $\mathrm{m}^{-1}(25 \mathrm{a} 13 \Omega \mathrm{m})$. Estes resultados foram influenciados pela presença de material argiloso e do nível freático. A área onde se realizou este perfil teria uma espessura maior dos depósitos recentes, sendo que o conteúdo de material grosso e a porosidade seriam relativamente menores neste local. Na profundidade teórica de $60 \mathrm{~m}$ (VMD-40); $\sigma$ aumenta de 55 até 85 mmhos.m ${ }^{-1}(18$ a $11 \Omega m)$. A diferença na condutividade do embasamento neste perfil pode ser explicada pela influência da fiação elétrica e a existência cercas metálicas, próximas à linha ensaiada. Outra explicação pode residir na ocorrência de maior alteração dos basaltos (geração de solo), os quais geram argilas por hidrólise dos silicatos, assim como pelo preenchimento das fraturas dos basaltos com estas argilas. Porém, segundo os resultados das SEVs e os dados litoestratigráficos dos poços, esta última opção é menos provável, embora não descartável.

\section{ZONA DE DISPERSÃO SALINA}

Para a identificação da zona de dispersão salina foram utilizados dados de uma SEV, de um caminhamento elétrico com dispositivo wenner e de um perfil eletromagnético, todos realizados a $50 \mathrm{~m}$ da linha da maré alta (Figura 4). A SEV foi feita paralela à linha de costa e os caminhamentos, por sua vez, transversais a ela. Os materiais sobre os quais se efetuaram os ensaios correspondem aos sedimentos marinhos. 


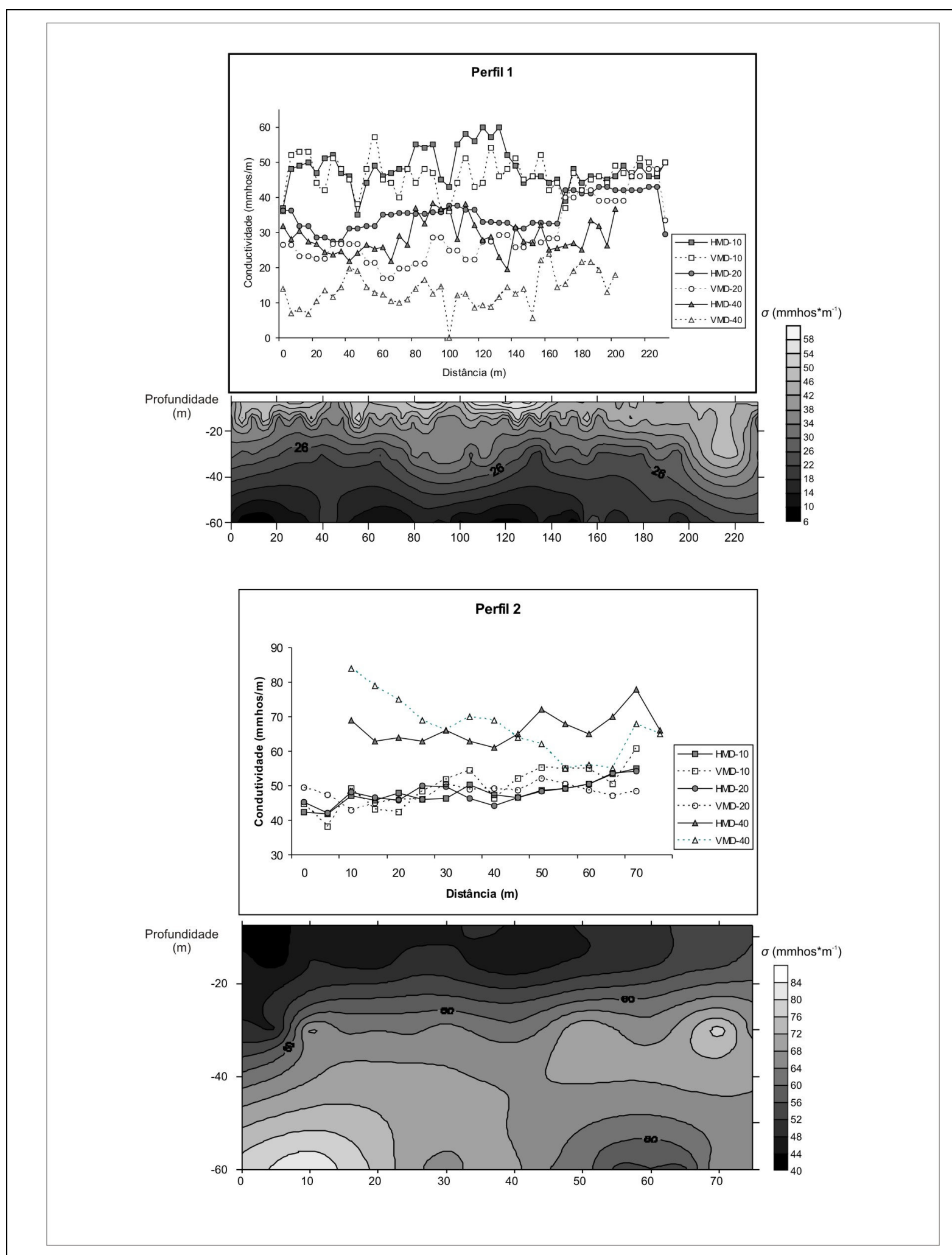

Figura 6 - Perfis de condutividade e interpolação dos dados obtidos com as configurações HMD e VMD (aberturas de 10, 20 e $40 \mathrm{~m}$ ).

Figure 6 - Conductivity section and data interpolation for each configuration used. 


\section{SEV e Caminhamento Elétrico}

A curva de inversão de resistividade aparente da SEVPPM19 é particularmente diferente das curvas mostradas anteriormente, mesmo considerando um modelo de quatro camadas (Figura 7). A camada superior é mais resistiva $(140 \Omega \mathrm{m})$ em relação às demais SEVs analisadas e apresenta pouca espessura $(1,1 \mathrm{~m})$. Esta camada corresponde com as areias que formam um terraço de cerca de $30 \mathrm{~m}$ de comprimento na forma de pequenas dunas. $O$ valor da sua resistividade indica alta porosidade, produto de sua consolidação incipiente.

A segunda camada, com resistividade de 6 $\Omega \mathrm{m}$, indicou a presença do nível freático e representa sedimentos arenosos com algum conteúdo de argilas, os quais estariam levemente saturados com água salina, sua espessura é de 2,4 $\mathrm{m}$. O conhecimento da geologia a priori foi muito importante na inversão final desta sondagem, sendo que condicionou os valores obtidos de resistividade de cada camada, já que dados de resistividade aparente podem ser ajustados a diferentes modelos conceituais, mesmo mantendo erro aceitável para a inversão final.

O terceiro horizonte do modelo apresentou o resultado mais interessante; nesta camada a o valor de resistividade foi de $1,1 \quad \Omega \mathrm{m}$ (910 mmhos. $\left.\mathrm{m}^{-1}\right)$. Este valor sugere a presença de sedimentos altamente saturados com água salgada, e seria, por conseguinte, o indicativo da presença da cunha salina. A camada atinge uma profundidade de $15,5 \mathrm{~m}$, sendo que sugere uma diminuição da espessura do aqüífero em direção ao mar. O embasamento mostra, no gráfico, um tramo final ascendente concordante com as outras SEVs, confirmando a efetividade desta SEV. O valor da resistividade do embasamento é relativo, o valor outorgado no modelo seria um ajuste para o tipo de rocha presente, a qual varia com a influencia do material argiloso no seu topo. $\mathrm{O}$ erro do ajuste final da SEVPPM19 foi de $15 \%$. Esta porcentagem é produto de uma maior dispersão dos dados considerados, influídos pela alta condutividade da água salinizada.

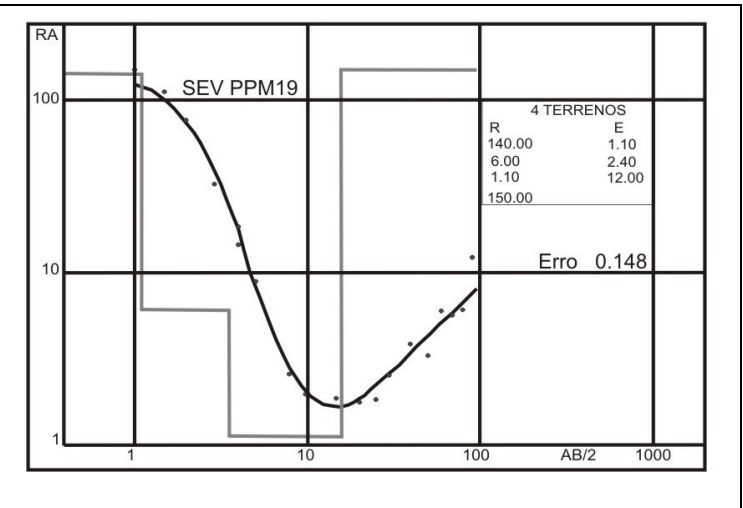

Figura 7: Resultados da inversão da SEV19.

Figure 7 - Inversion results for SEV 19.

O caminhamento elétrico foi realizado no ponto P3 (Figura 4). As aberturas utilizadas entre eletrodos foram de 2,4,8, e $16 \mathrm{~m}$, o comprimento total do caminhamento atingiu $0,21 \mathrm{~km}$.

A seção de resistividade modelada é mostrada na Figura 8. A seção corresponde com os sedimentos recentes que compõem a zona aqüífera. A parte superior dela se caracteriza por ter uma resistividade média entre 50 e $200 \Omega \mathrm{m}$ nos primeiros $3 \mathrm{~m}$ de profundidade. Estes valores sugerem a presença do material arenoso do cordão lunar nos primeiros $30 \mathrm{~m}$ de comprimento. A resistividade do corpo de sedimentos principal (após dos $16 \mathrm{~m}$ de distancia e $3 \mathrm{~m}$ de profundidade) é baixa, sendo que o seu valor médio seria de aproximadamente 15 $\Omega \mathrm{m}$, coincidindo com os valores de resistividade estimados pelas SEVs para à ZS. A baixa resistividade no tramo final desta seção do aquífero sugere, preliminarmente, a presença de alguma lente de argila. 


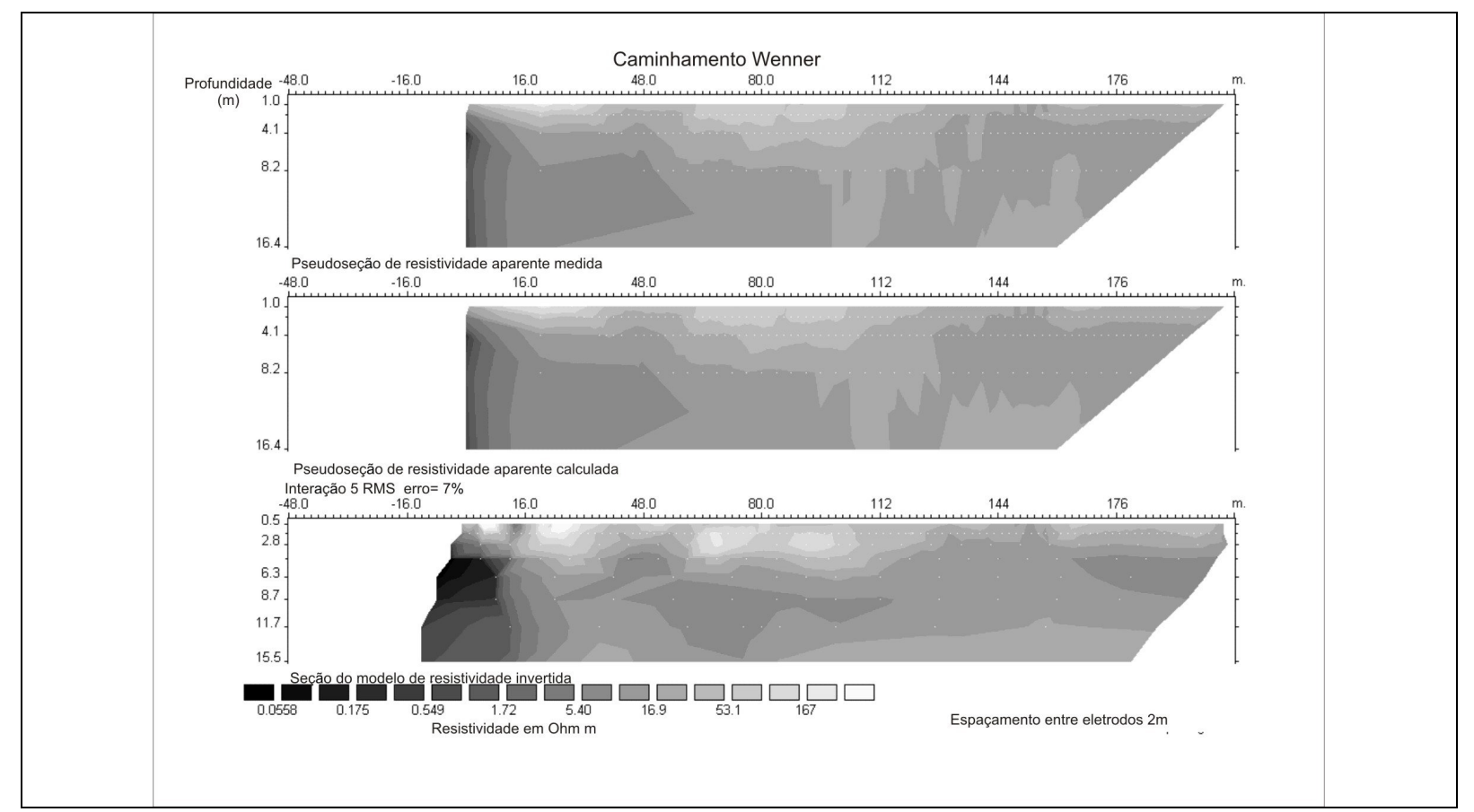

Figura 8: Resultados da inversão do caminhamento elétrico com arranjo Wenner. O ponto de-50 m indica a linha de maré alta.

Figure 8 - Wenner profiling inversion results. High tide point is at the distance of $-50 \mathrm{~m}$.

Após dos 3 metros de profundidade, a resistividade dos sedimentos apresentou valores muito baixos nos primeiros 16 metros de distância do caminhamento. Sendo que apresentou valores relativamente maiores no tramo final de esse intervalo. A tendência e forma das curvas de isorestividade sugerem a presença da zona de dispersão salina, a qual se encaixa nos sedimentos recentes até uma profundidade máxima de $15 \mathrm{~m}$, o seja a espessura total do aqüífero nesse setor. Com isto, a distância máxima que atinge a intrusão salina seria de aproximadamente $65 \mathrm{~m}$ para o interior do continente desde a linha de maré alta. Embora o caminhamento fosse realizado no setor nordeste da zona aqüífera, acredita-se que a condição do processo de intrusão salina e similar em toda a faixa costeira.

No perfil eletromagnético P3, as medições foram feitas a cada quatro metros, mantendo as aberturas de 10 e $20 \mathrm{~m}$ do instrumento porque foi assumida uma interface salina encaixada nos sedimentos do aquífero. O modo HMD-10 (profundidade de 7,5 m), nos $20 \mathrm{~m}$ iniciais ao longo do perfil, reflete valores de $\sigma$ de sedimentos arenosos saturados com água doce e água salgada (máximos entre 100 e 250 mmhos. $\mathrm{m}^{-1}$ ). Dos 20 aos $250 \mathrm{~m}$ no perfil, a $\sigma$ permanece quase constante, mas com valores maiores $\left(60\right.$ a 80 mmhos. $\left.\mathrm{m}^{-1}\right)$ em relação aos resultados dos perfis eletromagnéticos mostrados anteriormente. Este resultado sugere que a $\sigma$ seria influída principalmente pela salinização dos sedimentos, sendo que a distância deles em relação ao mar é menor. Por outro lado, as configurações VMD-10 e HMD-20, que representam uma profundidade teórica de $15 \mathrm{~m}$, indicaram a homogeneidade do aqüífero após 20 $\mathrm{m}$ de distância ao longo do perfil. Porém, o modo VMD-10 apresentou uma anomalia negativa antes dessa distância, tendo uma $\sigma$ máxima de 100 mmhos. $\mathrm{m}^{-1}(10 \Omega \mathrm{m})$. Esse tipo de anomalia, segundo McNeill (1980) e McDonald, Davies e Peart (2001) estaria associada à presença de corpos condutores estreitos e verticais; neste caso, a anomalia seria análoga a uma zona de dispersão salina de alto mergulho. Outra anomalia condutiva foi observada aos $220 \mathrm{~m}$ do perfil no registro do VMD-10; sendo que nesta posição estaria localizada uma caixa de alta tensão no subsolo. A sensibilidade das bobinas horizontais ficou evidente no modo VMD-20, particularmente nos primeiros $20 \mathrm{~m}$ ao longo da perfilagem, já que a $\sigma$ apresentou valores negativos ou próximos de zero. $\mathrm{O}$ valor máximo que atingiu foi de 150 mhos. $\mathrm{m}^{-1}(6,7 \Omega \mathrm{m})$. Esta situação se explica pela altíssima condutividade dos sedimentos saturados com água salgada nessa profundidade, e ao fato de que o condutivímetro utilizado não está capacitado para medir condutividades superiores a 1000 mmhos. $\mathrm{m}^{-1}$ (menores que $1 \Omega \mathrm{m}$ ). 


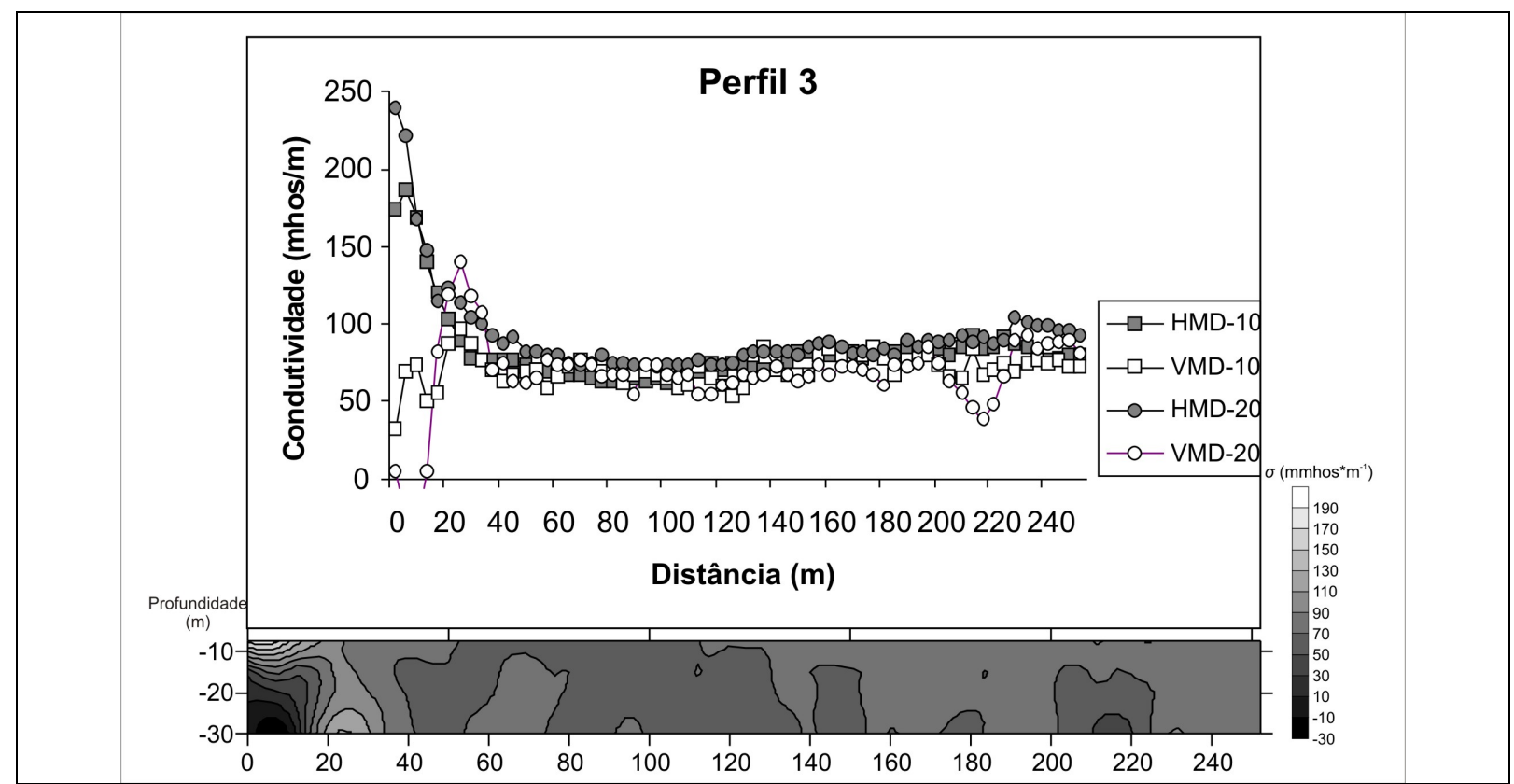

Figura 9 - Perfil eletromagnético 3, note-se a presença da interface água doce - água salgada nos sedimentos do aqüífero de Playa Panamá.

Figure 9 - Electromagnetic section number 3 showing the saline interface inside the sediments of Playa Panamá's aquifer.

Os resultados da avaliação geofísica da cunha salina mostraram uma interface rasa e de pequena extensão para dentro do continente. Os dados hidrogeoquímicos corroboraram este fato, analisando o conteúdo de cloretos em amostras coletadas em 8 poços (máximo de $25 \mathrm{mg} / \mathrm{L}$ ), e a condutância específica, a qual atingiu valores entre 350 e $485 \mu \mathrm{mhos} / \mathrm{cm}$.

\section{CONSIDERAÇÕES FINAIS}

O aquífero de Playa Panamá é essencialmente homogêneo e está composto por material grosso, sendo que lentes de argila se apresentam ocasionalmente, basicamente no topo do aqüífero, outorgando-lhe uma condição de semiconfinamento em alguns setores. Segundo a equação de Simandoux (WARD, 1990), a resistividade do fluido nos poros e no corpo do aqüífero dependerá da fração argilosa que este possa conter.

A geometria do aqüífero varia com a profundidade do topo do embasamento basáltico, a qual diminui com a distância em relação ao mar. Os registros estratigráficos dos poços, os resultados das SEVs e dos perfis elétricos e eletromagnéticos, confirmam esta situação. A presença de argilas em alguns setores no topo do aqüífero também foi refletida pelas técnicas geofísicas empregadas. Em geral, as SEVs apresentaram melhores resultados para a determinação das espessuras das camadas modeladas, e visaram um melhor entendimento da estratigrafia do subsolo. A condutívimetria evidenciou as poucas variações texturais laterais dos sedimentos do aqüífero. Esta técnica mostrou também maior sensibilidade com o incremento da abertura de separação entre as bobinas (aumento da profundidade), sendo que em aberturas maiores os resultados foram afetados por elementos como a fiação elétrica e objetos condutivos soterrados. Por isso, o conhecimento a priori do contexto geológico facilitou a interpretação dos resultados e ajudou a resolver os problemas de equivalência e calibragem, tanto no método eletromagnético quanto nas inversões no método elétrico. Os resultados da condutivimetria são qualitativos, porém, existe a possibilidade de inverter os dados de condutivimetria, possibilitando análises detalhadas das feições condutivas de elementos geológicos. Monteiro Santos (2004) aplicou um algoritmo matemático a partir de funções acumulativas. O resultado, é uma inversão $1 \mathrm{D}$ que pode ser utilizada inclusive com os dados de apenas dois espaçamentos. Esta inversão pode ser especialmente útil em estudos de intrusão salina, a qual pode ser usada igualmente como as inversões de caminhamentos elétricos. A inversão não foi usada neste trabalho devido a que o programa utilizado ainda está em fase de prova pelos seus autores.

A existência de uma única zona de dispersão salina foi sustentada no fato da homogeneidade do aqüífero. 
Para Custodio (1987), a existência de uma zona de dispersão evidente, existirá quando ela represente pequena porcentagem da espessura saturada; o encaixamento dela será menor com a diminuição da espessura e da permeabilidade do aquífero, e será maior com o aumento do fluxo de água doce. $\mathrm{O}$ emprego da corrente contínua (em suas duas técnicas) e da condutivimetria permitiu a identificação da cunha salina. Ambos os métodos mostraram-se muito sensíveis à presença dela, particularmente o caso das configurações VMD-10 e o VMD-20 na condutivimetria, que apresentaram valores de $\sigma$ superiores aos limites de detecção do instrumento. Os resultados geofísicos em Playa Panamá mostraram a presença da zona de dispersão salina a partir de uma profundidade superior a $3 \mathrm{~m}$, e uma distância de aproximadamente $65 \mathrm{~m}$ desde a linha de maré alta para o interior do continente. Neste caso, o seu encaixamento para dentro do continente estaria influenciado pela extração de água dos poços; pela menor espessura do aquíf́ero na proximidade do mar, mas, principalmente pela transmissividade deste, a qual é significativa por se tratar de um aqüífero livre.O valor de $\sigma$ do aqüífero em presença da interface salina excederia os 1000 mmhos. $\mathrm{m}^{-1}$, o valor mínimo associado a ela neste caso é de 100 mmhos.m ${ }^{-1}$, isso corresponde a uma faixa de resistividade mínima entre 1 e $10 \Omega \mathrm{m}$. Wilson, Ingham e McConchie (2006).afirmam que a resistividade da água do mar é de aproximadamente $0,3 \Omega \mathrm{m}$. Segundo eles, um corpo de sedimentos homogêneos sem presença de argila e saturados de água salgada, teria uma resistividade entre 5 a $10 \Omega \mathrm{m}$.

O conteúdo de cloretos e as condutâncias específicas dos poços de água em Playa Panamá não indicaram poluição por intrusão salina. Os dados sugerem, respectivamente, uma porcentagem menor ao $1 \%$ da composição e cerca do $16 \%$ da condutividade elétrica da água do mar.

A identificação da intrusão salina no aqüífero de Playa Panamá é de grande importância ambiental. O uso sustentável do reservatório hídrico pode ser planejado com ajuda desta informação e complementado com estudos hidrogeoquímicos e hidrodinâmicos detalhados. 


\section{REFERÊNCIAS}

ARIAS, M.E. La prospección geoeléctrica y electromagnética en dos dimensiones y su aplicación en la hidrogeología. Rev. Geol. América Central, San José, (27):21-26, 2002.

ARIAS SALGUERO, M., VARGAS, A., GUÈRIN, R. Geofísica aplicada al problema de la intrusión salina en los acuíferos costeros de Costa Rica. In: IGME (ed) Tecnología de la intrusión de agua de mar en acuíferos costeros: países mediterráneos, Madrid, 8 (1): 163-167, 2003.

ARELlanO, F.; VARGAS, A., Casos de Contaminación por intrusión salina en acuíferos costeros de la Península de Nicoya (Costa Rica). Rev. Geol. América Central, San José, (25):77-84, 2001.

CUSTODIO, E. Salt-fresh water interrelationships under natural conditions. In: CUSTÓDIO, E. E BRUGGEMAN G.A (eds). Groundwater problems in coastal areas. Studies and reports in hydrogeology. Belgica, UNESCO, 14-88, 1987.

DEIDDA, J.P., RANIERI, G., CASAS POSANTI, A., NUVOLI, M., ERRIU, S.; TAPIAS PANTEBRE, J.C. Delimitación de la intrusión salina en el acuífero aluvial de la Marina de Cardedu (Cerdeña centro oriental) a partir de medidas electromagnéticas en el dominio de frecuencias. In: IGME (ed) Tecnología de la intrusión de agua de mar en acuíferos costeros: países mediterráneos, Madrid, 8 (1): 197-202, 2003.

DENYER, P.; ARIAS, O. Geología del Norte de la Península de Nicoya. Rev. Geol. América Central, San José, (16):69-84, 1993.

GOMEZ, M. Estudio hidrogeológico Integral de las cuencas hidrográficas de los poblados el Coco y Ocotal, Carrillo, Guanacaste. - ECG, Universidad de Costa Rica, San José, Dissertação de Mestrado, 168p., 2005.

LOSILLA, M. Evidencia de amenazas a las aguas subterráneas de Costa Rica.In: Taller de aguas subterráneas, 1, Colegio Federado de Ingenieros, San José: 1-23, 1993.

HERRERA, W. Clima de Costa Rica. Universidad Estatal a Distancia, San José, v.2. 118 p., 1985.

I.M.N.- Instituto Meteorológico Nacional. Catastro de las series de precipitaciones medidas en Costa Rica. San José, Ministério de Recursos Naturales, Energia y Minas, 361 p. 1988.

MacDONALD, A.M.M, DAVIES, J., PEART,R.J. Geophysical methods for locating groundwater in low permeability sedimentary rocks: examples from southeast Nigeria. Journal of African Earth Sciences. (32)1, p.115-131. 2001.

Disponível em: http://www.sciencedirect.com/science.
McNEILL, J.D., Electromagnetic Terrain conductivity measurement at low induction numbers. Geonics, Technical Note TN-6, 1980. Disponível em: http://www.geonics.com/html/technicalnotes.html. Acesso em 10 jan. 2006.

McNEILL, J.D., EM34-3 measurements at two inter-coil spacings to reduce sensitivity to nearsurface material. Geonics, Technical Note TN-19, 1985. Disponível: (http://www.geonics.com/html/technicalnotes.html) Acesso em 10 jan. 2006.

McNEILL, J.D., Use of electromagnetic methods from groundwater studies. In: Ward, S.H (ed). Geotechnical and Enviromental Geophysics. v. 1, Investigations in Geophysics (5), Oklahoma, SEG, 191-218, 1990.

MONTEIRO SANTOS, F.A. 1-D laterally constrained inversion of EM34 profiling data. Journal of Applied Geophysics.(56):123-134, 2004. Disponível em: http://www.sciencedirect.com/science. Acesso em 10 jan 2006.

PROTTI, R. Geología y geofísica con fines hidrogeológicos en la planicie costera Jicaral-Santa Rita, península de Nicoya - ECG, Universidad de Costa Rica, San José, Dissertação de Licenciatura, $47 \mathrm{p}, 1981$.

SPIES, M., FRISCHKNECHT, F.C. Electromagnetic sounding. In: NABIGHMAN,M.N.(ed). Electromagnetic Methods in Applied Geophysics. v.2, Investigations in Geophysics (3), Oklahoma, SEG, 285-425, 1987.

WARD, S.H., Resistivity and induced polarization methods. In: Ward, S.H (ed). Geotechnical and Enviromental Geophysics. v. 1, Investigations in Geophysics (5), Oklahoma, SEG, 147-190, 1990.

WILSON, S.R., INGHAM, M. E McCONCHIE, J.A. The applicability of earth resistivity methods for saline interface definitions. Journal of Hidrology. (316): p.301-312, 2006.

Disponível em: http://www.sciencedirect.com/science. Acesso em 5 jan. 2007.

\section{AGRADECIMENTOS}

Agradece-se ao pessoal da Escuela Centroamericana de Geología (ECG) da Universidad de Costa Rica, particularmente a Mario Arias pelo empréstimo dos equipamentos utilizados; aos siguentes colegas geólogos: Natalia Montes, Pablo Herrera, Natalia Zamora, Alexander Padilla, Pedro Acosta, Catalina Vargas, Maria de los Angeles Molina e Oscar Lucke; ao pessoal do AyA, especialmente a Grace García, ao pessoal do ICT, e a ALHSUD. 